\title{
ReMashed - An Usability Study of a Recommender System for Mash-Ups for Learning
}

\author{
doi:10.3991/ijet.v5s1.1191
}

\author{
H. Drachsler ${ }^{1}$, D. Pecceu ${ }^{2}$, T. Arts ${ }^{2}$, E. Hutten², L. Rutledge ${ }^{2}$, P. van Rosmalen ${ }^{1}$, H. Hummel ${ }^{1}$ and R. Koper ${ }^{1}$ \\ ${ }^{1}$ Open University of the Netherlands, Centre for Learning Sciences and Technologies, Heerlen, Netherlands \\ ${ }^{2}$ Open University of the Netherlands, Computer Science Department, Heerlen, Netherlands
}

\begin{abstract}
The following article presents an usability study of a Mash-up Personal Learning Environment called ReMashed that recommends items from the emerging information of a Learning Network. In ReMashed users can specify certain Web 2.0 services and combine them in a Mash-Up Personal Learning Environment. The users can rate information from an emerging amount of Web 2.0 information of a Learning Network and train a recommender system for their particular needs. In total 49 participants from 8 different countries registered to evaluate the ReMashed system. The participants contributed Web 2.0 contents and used the recommender system for one month. The evaluation was concluded with an online questionnaire where most of the participants were positive about the ReMashed system and offered helpful ideas for future developments.
\end{abstract}

Index Terms-recommender systems, personal learning environments, informal learning, emergence.

\section{INTRODUCTION}

Nowadays, Internet users take advantage of services like iGoogle or Netvibes to create a personal view on information they are interested in. iGoogle and Netvibes offer a Personal Environment (PE) that allows their users to add and combine different information sources of the Internet at one place. The advantages for the users are obvious; they can observe and read the latest information without browsing to the original source. Further, by integrating Web 2.0 services like Flickr, Delicious or Slideshare the user can follow other users and integrate social networks into such a PE. The fuel for this interoperability is the XML standard RSS (Really Simple Syndication). Every common service or blogging software takes advantage of it to spread its information in the Internet. RSS enables users of PEs to be notified about latest update on their favorite information sources.

The existing of PEs inspired research in the Technology-Enhanced Learning field to explore this technology for learning purposes. As a consequence Personal Learning Environments (PLEs) where invented for learners [14]. PLEs are a kind of instance of the Learning Network concept [5] and therefore share several characteristics with it. Learning Networks consist of user-generated-content by lifelong learners who are able to create, comment, tag,

Authors' efforts were (partly) funded by the European Commission in TENCompetence (IST-2004-02787) http://www.tencompetence.org. rate, share and study learning material. Lifelong learners are acting much more self-directed and they are responsible for their own learning pace and path [6, 7]. In addition, the resources for their learning might come from many different sources: expert communities, work context, training or even friends might offer an opportunity for their competence development. Learning Networks take advantage of the wisdom of the crowd theory and Web 2.0 developments. By the emerging behavior of such a Learning Network it may consist of a large amount of learning materials. Learning Networks are bottom-up driven because their contents are not created by specially trained or paid domain experts rather than by their members. They explicitly address informal learning because no assessment or accreditation process is connected to them.

PLEs also support informal learning as they require no institutional background, are free of use and focus on the learner instead of institutional needs like student management or assessments. The learners do not participate in formal courses and neither receive any certification for their competence development. Similar to the PE concept, PLEs are used to combine different sources of information on the web that is supportive for the individual learner regarding the personal competence development. Most of the time, the sources are free of use and selected by the learner. PLEs are therefore in contrast to existing Virtual Learning Environments (VLEs) like Moodle or Blackboard that are offered by institutions to distribute learning material to learners. VLEs focus more on the institutional needs and offer support for business processes of educational institutes like Universities. Although, PLEs are most appropriate for informal learning, educational scenarios are imaginable where PLEs become integrated into formal courses as well. However, they remain as an addition to the formal procedures in schools and universities but this may change in the future.

A common problem for Mash-Ups and PLEs is the amount of data that is emerging already in a short time frame. The learners can be overwhelmed by the information they get or they might have problems judging the most suitable learning material for their personal competence development. On the one hand, PLEs provide learners much more freedom to choose learning material from a number of providers, on the other hand the learners have an increasing responsibility for the results of their own learning process. In such a situation it is hard to get an overview of available learning material and to identify the most suitable for them [8]. A solution towards this prob- 
lem might be recommender system technology. The main purpose of recommender systems on the Internet is to preselect information a user might be interested in. For instance, the well-known company amazon.com [9] is using a recommender system to direct the attention of their users to other products in their collection. The motivation for a recommender system for Mash-Up Personal Learning Environments is to improve the 'educational provision'; to offer a better goal attainment and to spend less time to find suitable learning material. Therefore, we developed a recommender system that offers advice to learners based on their Web 2.0 resources regarding the most suitable learning materials to meet their individual competence development. The combination of different Web 2.0 services to recommend information based on mashed tagand rating-data was not done so far and especially not for learners in Mash-Up Personal Learning Environments. Thus, ReMashed offers a new approach by mashing data of users from various Web 2.0 service to provide tailored recommendation to them.

The system takes advantage of bottom-up emerging information like tags and ratings from user-generatedcontent. Traditional recommendation techniques are adjusted with learning related characteristics to provide pedagogical recommendations to the learners [10].

In the following sections we first discuss related work (section two). After that we introduce the ReMashed system (section three). We present the results of the usability analysis of a first ReMashed pilot (section four) and finally discuss the findings and its impact for future research (section five).

\section{RELATED WORK}

Nowadays, 'mashing' information becomes a broadly used activity on the Internet. Various tools provide the opportunity to combine information from other sources in a new way (Yahoo Pipes, Dapper, Openkapow, Chickenfoot, Greezemonkey etc.). The users do not need special programming skills to use them in order to combine different Internet sources. The users can make advantage of public APIs of Web 2.0 services and standardized XML formats like JSON to mash data in a new way.

In the Technology-Enhanced Learning field several European projects address these bottom-up approaches of creating and sharing knowledge. The TENcompetence project addresses learners in informal Learning Networks [11]. The iCamp project explicitly addresses the Mash-Up Personal Learning Environments and calls them MUPPLE [12]. They created an easy to program and flexible environment that allows learners to create their own MUPPLE for certain learning activities. However, these systems face the problem that the emerging behavior of these bottom-up approaches gathers large amounts of data. With the ReMashed system we want to offer navigation support for Mash-up PLEs to support learners to find the most suitable data for their learning goals and competence development plans.

From the recommender system research extensive research is going on to take advantage of the tags in recommender systems [13-16]. Single services like Delicious or Flickr offer recommendations to their users based on their data and also researcher take advantage of single Web 2.0 services to create recommender systems $[14,17]$.
The combination of different Web 2.0 services to recommend information based on mashed tag and rating data is still lacking, especially for the support of learners in Mash-Up Personal Learning Environments. Thus, ReMashed offers a new approach by mashing data of users from various Web 2.0 service to provide pedagogical sound recommendation to them.

\section{THE REMASHED SYSTEM}

A prominent example of ReMashed from a different domain is the MovieLens project created by the GroupLens research group [18]. They offer a movie portal where users can add, rate and receive recommendations for movies. Besides this attractive service GroupLens created a frequently used data set for the development of recommendation algorithms [19].

ReMashed stays in the same line, it is intended for three things: 1 . to provide a recommender system for Mash-up Personal Learning Environments to learners, 2. to offer an environment for testing new recommendation approaches and methods for researchers, and 3. to create informal user-generated-content data sets for researchers to evaluated new recommendation algorithms to support learners in informal Learning Networks.

Differently to MovieLens and famous e-commerce recommender systems which follow simple semantics like 'People who liked X also liked Y', ReMashed needs to apply more knowledge driven recommendation algorithms to take pedagogical reasoning into account [20].One approach could be to filter the most suitable information according to the learning goals and knowledge level of the current learner. Most promising therefore are contextaware recommender systems [21].

In order to test recommendation approaches for Mash-Up Personal Learning Environments we designed a Mash-up that enables learners to integrate their sources from Web 2.0 services (Flickr, Delicious, Blogs, and Slideshare). The system allows the learners to personalize the emerging information of a community to their preferences. Therefore, the learners rate information of the Web 2.0 services in order to define which contributions of other members they like and do not like. ReMashed takes the preferences into account to offer tailored recommendation to the learner.

It uses collaborative filtering techniques [22] to generate recommendations. It works by matching together users with similar opinions by their tags and ratings about different resources. Each member of the system has a 'neighborhood' of other like-minded users. Ratings and tags from these neighbors are used to create personalized recommendations for the current learner. The recommender system combines tag and rating based collaborative filtering algorithms in a recommendation strategy. Such a recommendation strategy defines certain situations that trigger when which recommendation algorithm should be used.

After a learner signed in for the first time the system has no rating information from the new user (cold-start situation). Thus, the recommender system uses the tagging information of the specified Web2.0 services from the user to offer first recommendations. It computes the similarity between the tag cloud of the current learner with other learners and resources. 


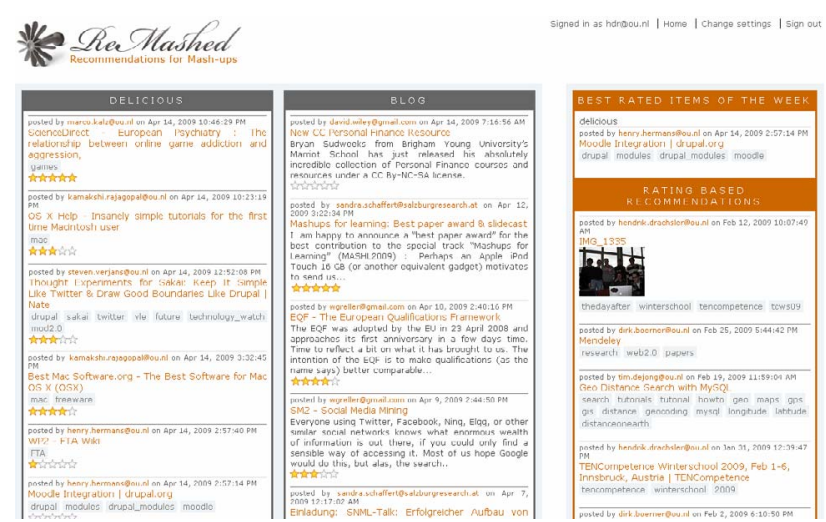

Figure 1. Overview page of the ReMashed system. On the left side, the mashed information from delicious and blogs are shown. On the right side, the rating based recommendations for the current learner are shown.

Once the learner started to rate information of the Web 2.0 sources of other users the recommender system also uses the ratings to offer recommendations besides the tag based recommendations.

ReMashed consists of five sub-systems (see Figure 2), a user interface, a data collector, a user logger, a recommender system and the Duine prediction engine (http://duineframework.org).

1. The User Interface is responsible for user interaction, authentication of users, registration of new users and updating of user data.

2. The Data Collector establishes the connection between the Web 2.0 services and gathers new data into the ReMashed database via a CRON job that runs every hour.

3. The Logger offers logging methods to the other subsystems. It stores log messages and monitors user actions in the system.

4. The Recommender System composes the recommendations for every user and puts them into the database. It allows implementing new recommendation algorithms in PHP but it also provides a connection to the Duine 4.0 prediction engine based on JAVA that can be used to compute recommendations for the learning resource.

5. The Duine Prediction Engine offers extensive options for configuring various recommender algorithms. It provides a sample of most common recommendation algorithms that can be combined in algorithm strategies, thus it is possible to create new recommendation strategies that follow pedagogical rules.

ReMashed is an Open Source project based on PHP5, Zend Framework 1.7 with the Dojo Ajax framework, MySQL database, Apache Server and the Duine recommendation engine. ReMashed is following the ModelView-Controller programming concept and is therefore fully object oriented. The source code of version ReMashed 1.0 is available at the Dspace repository of the Open University http://dspace.ou.nl/handle/1820/2187. The system can be tested at http://remashed.ou.nl.

\section{UsAbILITy STUdy OF THE REMASHEd SySTEM}

To evaluate the usability of the system we started a satisfaction analysis at the TENCompetence Winterschool 2009. Besides the participants of the Winterschool also external users where allowed to sign up for the evaluation phase. In total 49 people from 8 different countries subscribed to the evaluation and contributed content, tags and ratings to the ReMashed prototype. The evaluation phase ran for one month and was concluded with an online recall questionnaire. We received answers from 19 participants in total, thus we had a response rate of $38 \%$. In this section we present the most relevant answers from the online recall questionnaire regarding the usability with the ReMashed system. The answers regarding the use of Web 2.0 services can be found in Table 1 . The questions about the usability with the ReMashed system are shown in Table 2 and Table 3. Because the questions were not always answered by all 19 participants we added the total amount of answers per questions in Table 2 and Table 3.

In Table 2 we asked questions regarding the general usability with the ReMashed system and the offered recommendations. $63 \%(n=12)$ of the participants were overall satisfied with the ReMashed system. To further analyze the impact of our recommendation strategy, we asked the learners if they were more satisfied with the recommendation given in the beginning or at the end of the experiment (Table 2, questions 2 to 5). We wanted to know if the learners noticed any differences in the given recommendation over time, since the cold-start situation of the rating based algorithm was present in the beginning.

Further, the rating base recommendation should have become more accurate over time. $20 \%(n=3)$ of the participants were very satisfied and $40 \%(n=6)$ were satisfied with the tag-based recommendation in the beginning of the test phase. Thus, our own tag-based algorithm did a reasonable job regarding the cold-start of the system. The participants were at the end evaluation phase no longer very satisfied with the tag-based algorithm, but still $69 \%$ $(n=11)$ were satisfied with its recommendations. Regarding the rating-based algorithm surprisingly no differences were identified between the start and the end of the evaluation phase by the participants. They rated both time frames similar.

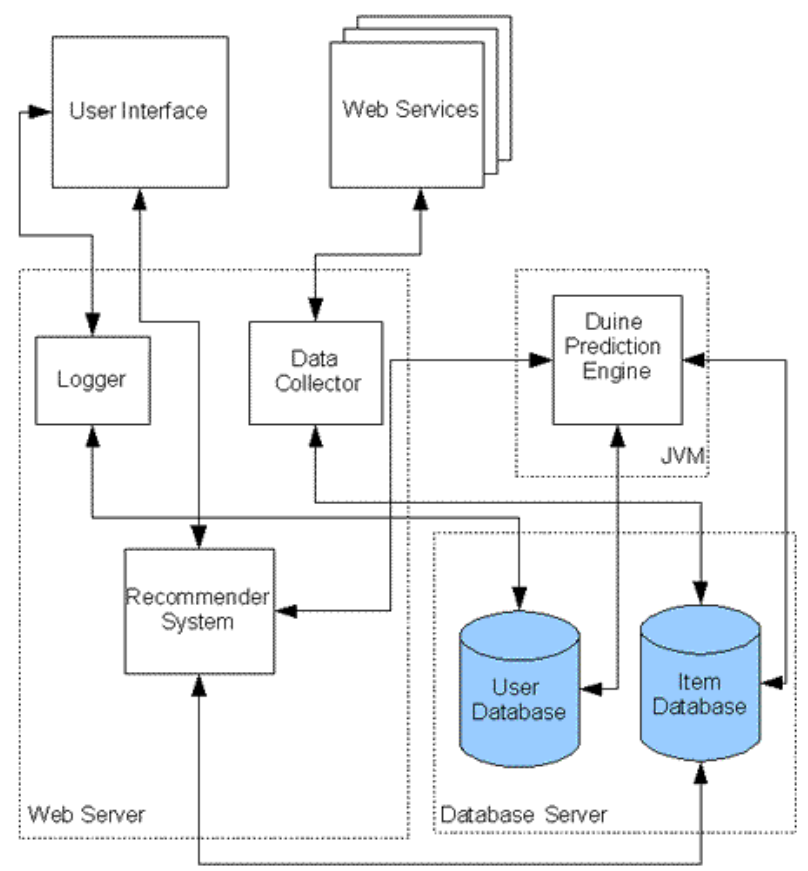

Figure 2. Technical architecture of the ReMashed system. 
TABLE I.

GENERAL STATEMENTS ABOUT THE USAGE OF WEB 2.0 SERVICES AND THEIR INTEGRATION IN THE REMASHED SYSTEM (TOTAL AMOUNT N = $19=100 \%)$

\begin{tabular}{|l|c|c|c|c|c|}
\hline \multicolumn{1}{|c|}{ Questions } & \multicolumn{4}{|c|}{ Values } \\
\hline \multicolumn{1}{|c|}{$\begin{array}{c}\text { Strongly } \\
\text { agree }\end{array}$} & Agree & Neutral & Disagree & $\begin{array}{c}\text { Strongly } \\
\text { disagree }\end{array}$ \\
\hline $\begin{array}{l}\text { I keep track of my } \\
\text { work results on a blog } \\
\text { or research diary. }\end{array}$ & $\begin{array}{c}16 \% \\
(\mathrm{n}=3)\end{array}$ & $\begin{array}{c}5 \% \\
(\mathrm{n}=1)\end{array}$ & $\begin{array}{c}32 \% \\
(\mathrm{n}=6)\end{array}$ & $\begin{array}{c}11 \% \\
(\mathrm{n}=2)\end{array}$ & $\begin{array}{c}37 \% \\
(\mathrm{n}=7)\end{array}$ \\
\hline $\begin{array}{l}\text { I bookmark interesting } \\
\text { resources in a social } \\
\text { book-marking tool like } \\
\text { Delicious. }\end{array}$ & $\begin{array}{c}42 \% \\
(\mathrm{n}=8)\end{array}$ & $\begin{array}{c}42 \% \\
(\mathrm{n}=8)\end{array}$ & $\begin{array}{c}5 \% \\
(\mathrm{n}=1)\end{array}$ & $\begin{array}{c}5 \% \\
(\mathrm{n}=1)\end{array}$ & $\begin{array}{c}5 \% \\
(\mathrm{n}=1)\end{array}$ \\
\hline $\begin{array}{l}\text { I upload pictures to a } \\
\text { picture service like } \\
\text { Flickr. }\end{array}$ & $\begin{array}{c}5 \% \\
(\mathrm{n}=1)\end{array}$ & $\begin{array}{c}32 \% \\
(\mathrm{n}=6)\end{array}$ & $\begin{array}{c}21 \% \\
(\mathrm{n}=4)\end{array}$ & $\begin{array}{c}26 \% \\
(\mathrm{n}=5)\end{array}$ & $\begin{array}{c}16 \% \\
(\mathrm{n}=3)\end{array}$ \\
\hline $\begin{array}{l}\text { I upload my presenta- } \\
\text { tions to a presentation } \\
\text { service like Slideshare. }\end{array}$ & $\begin{array}{c}11 \% \\
(\mathrm{n}=2)\end{array}$ & $\begin{array}{c}26 \% \\
(\mathrm{n}=5)\end{array}$ & $\begin{array}{c}21 \% \\
(\mathrm{n}=4)\end{array}$ & $\begin{array}{c}21 \% \\
(\mathrm{n}=4)\end{array}$ & $\begin{array}{c}17 \% \\
(\mathrm{n}=5)\end{array}$ \\
\hline $\begin{array}{l}\text { I use a micro blogging } \\
\text { tool like Twitter. }\end{array}$ & $\begin{array}{c}11 \% \\
(\mathrm{n}=2)\end{array}$ & $\begin{array}{c}21 \% \\
(\mathrm{n}=4)\end{array}$ & $\begin{array}{c}11 \% \\
(\mathrm{n}=2)\end{array}$ & $\begin{array}{c}21 \% \\
(\mathrm{n}=4)\end{array}$ & $\begin{array}{c}37 \% \\
(\mathrm{n}=7)\end{array}$ \\
\hline $\begin{array}{l}\text { I upload video streams } \\
\text { (movies) to a movie } \\
\text { sharing system like } \\
\text { YouTube. }\end{array}$ & $\begin{array}{c}0 \% \\
(\mathrm{n}=0)\end{array}$ & $\begin{array}{c}15 \% \\
(\mathrm{n}=3)\end{array}$ & $\begin{array}{c}37 \% \\
(\mathrm{n}=7)\end{array}$ & $\begin{array}{c}26 \% \\
(\mathrm{n}=5)\end{array}$ & $\begin{array}{c}21 \% \\
(\mathrm{n}=4)\end{array}$ \\
\hline $\begin{array}{l}\text { I use YouTube to add / } \\
\text { bookmark movies I } \\
\text { like to my account. }\end{array}$ & $\begin{array}{c}5 \% \\
(\mathrm{n}=1)\end{array}$ & $\begin{array}{c}32 \% \\
(\mathrm{n}=6)\end{array}$ & $\begin{array}{c}16 \% \\
(\mathrm{n}=3)\end{array}$ & $\begin{array}{c}16 \% \\
(\mathrm{n}=3)\end{array}$ & $\begin{array}{c}32 \% \\
(\mathrm{n}=6)\end{array}$ \\
\hline
\end{tabular}

TABLE II.

QUESTIONS REGARDING THE SATISFACTION OF THE PARTICIPANTS REGARDING THE REMASHED SYSTEM.

\begin{tabular}{|l|c|c|c|c|c|}
\hline \multicolumn{1}{|c|}{ Questions } & \multicolumn{5}{|c|}{ Values } \\
\hline & $\begin{array}{c}\text { Very } \\
\text { satisfied }\end{array}$ & Satisfied & $\begin{array}{c}\text { Un- } \\
\text { satisfied }\end{array}$ & $\begin{array}{c}\text { Very } \\
\text { unsatis- } \\
\text { fied }\end{array}$ & Amounts \\
\hline $\begin{array}{l}\text { How satisfied are you } \\
\text { overall with the Re- } \\
\text { Mashed system? }\end{array}$ & $\begin{array}{c}5 \% \\
(\mathrm{n}=1)\end{array}$ & $\begin{array}{c}58 \% \\
(\mathrm{n}=11)\end{array}$ & $\begin{array}{c}26 \% \\
(\mathrm{n}=5)\end{array}$ & $\begin{array}{c}11 \% \\
(\mathrm{n}=2)\end{array}$ & $\begin{array}{c}100 \% \\
(\mathrm{n}=15)\end{array}$ \\
\hline $\begin{array}{l}\text { How satisfied have } \\
\text { you been with the tag- } \\
\text { based algorithm in the } \\
\text { beginning of the Re- } \\
\text { Mashed pilot? }\end{array}$ & $\begin{array}{c}20 \% \\
(\mathrm{n}=3)\end{array}$ & $\begin{array}{c}40 \% \\
(\mathrm{n}=6)\end{array}$ & $\begin{array}{c}27 \% \\
(\mathrm{n}=4)\end{array}$ & $\begin{array}{c}13 \% \\
(\mathrm{n}=2)\end{array}$ & $\begin{array}{c}100 \% \\
(\mathrm{n}=16)\end{array}$ \\
\hline $\begin{array}{l}\text { How satisfied are you } \\
\text { now with the tag-based } \\
\text { algorithm at the end of } \\
\text { the pilot? }\end{array}$ & $\begin{array}{c}0 \% \\
(\mathrm{n}=0)\end{array}$ & $\begin{array}{c}69 \% \\
(\mathrm{n}=11)\end{array}$ & $\begin{array}{c}19 \% \\
(\mathrm{n}=3)\end{array}$ & $\begin{array}{c}13 \% \\
(\mathrm{n}=2)\end{array}$ & $\begin{array}{c}100 \% \\
(\mathrm{n}=16)\end{array}$ \\
\hline $\begin{array}{l}\text { How satisfied have } \\
\text { you been with the } \\
\text { rating-based algorithm } \\
\text { after it appeared in the } \\
\text { system? }\end{array}$ & $\begin{array}{c}8 \% \\
(\mathrm{n}=1)\end{array}$ & $\begin{array}{c}53 \% \\
(\mathrm{n}=7)\end{array}$ & $\begin{array}{c}31 \% \\
(\mathrm{n}=4)\end{array}$ & $\begin{array}{c}8 \% \\
(\mathrm{n}=1)\end{array}$ & $\begin{array}{c}100 \% \\
(\mathrm{n}=14)\end{array}$ \\
\hline $\begin{array}{l}\text { How satisfied are you } \\
\text { now with the rating- } \\
\text { based algorithm at the } \\
\text { end of the pilot? }\end{array}$ & $\begin{array}{c}8 \% \\
(\mathrm{n}=1)\end{array}$ & $\begin{array}{c}54 \% \\
(\mathrm{n}=7)\end{array}$ & $\begin{array}{c}31 \% \\
(\mathrm{n}=4)\end{array}$ & $\begin{array}{c}8 \% \\
(\mathrm{n}=1)\end{array}$ & $\begin{array}{c}100 \% \\
(\mathrm{n}=13)\end{array}$ \\
\hline $\begin{array}{l}\text { How satisfied are you } \\
\text { overall with the Re- } \\
\text { Mashed system? }\end{array}$ & $\begin{array}{c}5 \% \\
(\mathrm{n}=1)\end{array}$ & $\begin{array}{c}58 \% \\
(\mathrm{n}=11)\end{array}$ & $\begin{array}{c}26 \% \\
(\mathrm{n}=5)\end{array}$ & $\begin{array}{c}11 \% \\
(\mathrm{n}=2)\end{array}$ & $\begin{array}{c}100 \% \\
(\mathrm{n}=15)\end{array}$ \\
\hline
\end{tabular}

TABLE III.

QUESTION REGARDING THE USABILITY OF THE PARTICIPANTS REGARDING THE REMASHED SYSTEM.

\begin{tabular}{|l|c|c|c|}
\hline \multicolumn{1}{|c|}{ Question } & \multicolumn{2}{|c|}{ Values } & Amount \\
\hline & $\begin{array}{c}\text { Tag-based } \\
\text { recommenda- } \\
\text { tion }\end{array}$ & $\begin{array}{c}\text { Rating-based } \\
\text { recommenda- } \\
\text { tion }\end{array}$ & \\
\hline $\begin{array}{l}\text { Which recommenda- } \\
\text { tion technology did } \\
\text { satisfy you more at the } \\
\text { end of the ReMashed } \\
\text { pilot? }\end{array}$ & $\begin{array}{c}58 \% \\
(\mathrm{n}=7)\end{array}$ & $\begin{array}{l}42 \% \\
(\mathrm{n}=5)\end{array}$ & $\begin{array}{c}100 \% \\
(\mathrm{n}=12)\end{array}$ \\
\hline
\end{tabular}

In Table 3 we asked the participants for the ultimate choice between the tag-based algorithm and the ratingbased algorithm. Which recommendation technology did satisfy them more at the end of the ReMashed pilot? We see a tendency that people were more satisfied with the tag-based recommendations. Reasons for that could be plenty; the participants could have rated to less so that the rating-based algorithm did not improve enough over time or appeared to late in the evaluation phase because the participants did not provide enough ratings.

At the end of the questionnaire we offered an open question for general remarks. This opportunity was used by 13 participants. The most frequent remarks where regarding 1. privacy issues, 2. static behavior of the system, 3 . interoperability, and 4 . influencing the provided recommendations.

Regarding 1, some of the participants were afraid that their private data from the Web 2.0 service would be fetched and used in the system, therefore they did not offer all their service accounts to the system. We stressed in the start phase of the evaluation that only public data can be used but some people missed this information. To prevent this for future evaluations we will add a hint to the user profile.

The remarks regarding 2, the static behavior of the system addressed missing features for collaboration like a live chat or Google tools. In order to attract participants for future evaluation we either have to extend the functionality of the current ReMashed system towards a fully scaled PLE or develop a web service that can be connected to existing Mash-Up Personal Learning Environments.

The remarks regarding 3 , the interoperability goes towards the direction of the web service development. Many participants asked for RSS feeds of the recommendations to reintegrate them again in their PLEs. This motivates us to develop a recommender system web service for usergenerated-content.

Finally, the participants wanted to have the opportunity to rate the recommendation they received. This feature was not provided by the system during the first evaluation phase. Additionally, they asked for an overview list of all people that contribute to the system and an overview page of their own ratings.

\section{CONCLUSIONS AND FUtURE RESEARCH}

This article presented the ReMashed system a Mash-up Personal Learning Environment that implies a recommender system to recommend information from the emerging information of a Learning Network. The article showed the design and implementation of the recom- 
mender system in a Mash-Up Personal Learning Environment. It further presented the results of a usability study with 49 users.

The most obvious future research will be the evaluation of new recommendation algorithms regarding their impact on learners in informal Learning Networks. Therefore, we first want to review suitable algorithms and adjust them to our goals.

Based on the usability analysis we want to develop ReMashed further in two different ways. One way is the integration of additional PLE features to have an attractive environment for participants for future experiments. The other way is the development of a web service to offer recommendation to other Mash-Up Personal Learning Environments. The user should be able to specify sources and receive recommendation via RSS for their PLEs.

The challenging part thereby is to get ratings into the system. This can be done with a widget that can be integrated into the PLE of the users. Thus, we have to cut the data set into smaller pieces and provide users with a selection of them. The users can rate the items on a frequently base in order to train the recommender system for their needs. This widget approach is rather important as the collected data from the Web 2.0 services grow faster than the ratings in the system.

\section{REFERENCES}

[1] S. Wilson, Future VLE - The Visual Version, last accessed: 16.04.2009 at http://zope.cetis.ac.uk/members/scott/blogview?ent ry $=20050125170206,2005$.

[2] F. Wild, M. Kalz, and M. Palmer (eds.), "Mash-Up Personal Learning Environments," in CEUR Workshop Proceedings, vol. 388, Maastricht, The Netherlands, 2008.

[3] O. Liber and M. Johnson, "Personal Learning Environments," in Interactive Learning Environments, vol. 16, pp. 1-2, 2008.

[4] O. Liber, "Colloquia - a conversation manager," in Campus-Wide Information Systems, vol. 17, pp. 56-61, 2000.

[5] R. Koper and C. Tattersall, "New directions for lifelong learning using network technologies," in British Journal of Educational Technology, vol. 35, pp. 689-700, 2004.

[6] N. Longworth, Lifelong learning in action - Transforming education in the 21st century. Kogan Page, London, 2003.

[7] T.J. Shuell, "Designing instructional computing systems for meaningful learning,” in M.Jones, P.H.Winne (eds.): Adaptive learning environments, pp. 19-54, Berlin: Springer, 1992.

[8] H. Drachsler, H.G.K. Hummel, and R. Koper, "Personal recommender systems for learners in lifelong learning: requirements, techniques and model," in International Journal of Learning Technology, vol. 3, pp. 404-423, 2008

[9] G. Linden, B. Smith, and J. York, “Amazon.com recommendations: Item-to-item collaborative filtering,” in IEEE Internet Computing, vol. 7, pp. 76-80, 2003.

[10] H. Drachsler et al., "ReMashed - Recommendations for Mash-Up Personal Learning Environments", in Cress, U., Dimitrova, V., Specht, M. (eds.): Learning in the Synergy of Multiple Disciplines, EC-TEL 2009, vol. 5794, pp. 788-793, Springer, 2009. (doi:10.1007/978-3-642-04636-0_85)

[11] R. Koper and M. Specht, "TenCompetence: Lifelong Competence Development and Learning”, in Dr. Sicilia, M.A. (ed.): Competencies in Organizational E-Learning: Concepts and Tools, 2006.

[12] F. Wild, F. Moedritscher, and S.E. Sigurdarson, "Designing for Change: Mash-Up Personal Learning Environments,” in eLearning Papers, vol. 9, 2008.

[13] H. Wu, M. Zubair, and K. Maly, "Harvesting social knowledge from folksonomies," in 7th conference on Hypertext and Hypermedia, pp. 111-114, ACM New York, NY, USA, 2006.

[14] N. Garg and I. Weber, "Personalized, interactive tag recommendation for flickr”, Recommender Systems 2009, pp. 67-74, ACM New York, NY, USA, 2008.
[15] P. Symeonidis, A. Nanopoulos, and Y. Manolopoulos, "Tag recommendations based on tensor dimensionality reduction", in $R e$ commender Systems 2008, pp. 43-50, ACM New York, NY, USA, 2008. (doi:10.1145/1454008.1454017)

[16] A. Shepitsen, J. Gemmell, B. Mobasher, and R. Burke, "Personalized recommendation in social tagging systems using hierarchical clustering,” in Recommender Systems 2008, pp. 259-266, ACM New York, NY, USA, 2008.

[17] B. Sigurbjörnsson and R. Van Zwol, "Flickr tag recommendation based on collective knowledge", in 17th international conference on World Wide Web, pp. 327-336, ACM New York, NY, USA, 2008.

[18] J.A. Konstan, B.N. Miller, D. Maltz, J.L. Herlocker, L.R. Gordon, and J. Riedl, "GroupLens: applying collaborative filtering to Usenet news," in Communications of the ACM, vol. 40, pp. 77-87, ACM New York, NY, USA, 1997.

[19] D. O'Sullivan, D. Wilson, and B. Smyth, "Improving Case-Based Recommendation A Collaborative Filtering Approach," in 6th European Conference on Case-Based Reasoning, ECCBR, vol. 2416, LNAI Berlin: Springer, 2002.

[20] H. Drachsler, H.G.K. Hummel, and R. Koper, "Identifying the Goal, User model and Conditions of Recommender Systems for Formal and Informal Learning,” in Journal of Digital Information, vol. 10, no. 2, 2009.

[21] G. Adomavicius, R. Sankaranarayanan, S. Sen, and A. Tuzhilin, "Incorporating contextual information in recommender systems using a multidimensional approach," in ACM Transactions on Information Systems (TOIS), vol. 23, pp. 103-145, 2005.

[22] J.L. Herlocker, J.A. Konstan, J. Riedl, "Explaining collaborative filtering recommendations," in Proceedings of the ACM conference on computer supported cooperative work, pp. 241-250, 2000.

\section{AUTHORS}

H. Drachsler is Assistant Professor at the Centre for Learning Sciences and Technologies (CELSTEC), Open University of the Netherlands, PO-Box 2960, 6401 DL Heerlen, The Netherlands (hendrik.drachsler@ou.nl).

L. Rutledge is Assistant Professor at the Computer Science Department at the Open University of the Netherlands, PO-Box 2960, 6401 DL Heerlen (lloyd.rutledge@ou.nl).

P. van Rosmalen is Associated Professor at the Centre for Learning Sciences and Technologies (CELSTEC), Open University of the Netherlands, PO-Box 2960, 6401 DL Heerlen, The Netherlands (peter.vanrosmalen@ou.nl).

H. Hummel is Associated Professor at the Centre for Learning Sciences and Technologies (CELSTEC), Open University of the Netherlands, PO-Box 2960, 6401 DL Heerlen, The Netherlands (hans.hummel@ou.nl).

D. Pecceu, is student at the Computer Science Department at the Open University of the Netherlands, PO-Box 2960, 6401 DL Heerlen (pecceu@studie.ou.nl).

T. Arts, is student at the Computer Science Department at the Open University of the Netherlands, PO-Box 2960, 6401 DL Heerlen (tg.arts@studie.ou.nl).

E. Hutten, is student at the Computer Science Department at the Open University of the Netherlands, PO-Box 2960, 6401 DL Heerlen (ekh.hutten@studie.ou.nl).

R. Koper is the Dean of the Centre for Learning Sciences and Technologies (CELSTEC), Open University of the Netherlands, PO-Box 2960, 6401 DL Heerlen, The Netherlands (rob.koper@ou.nl).

Authors' efforts were (partly) funded by the European Commission in TENCompetence (IST-2004-02787) (http://www.tencompetence.org).

This article was modified from a presentation at the International Conference of Interactive Computer Aided Learning ICL2009, September 2009 in Villach, Austria. Submitted 11 September 2009. Published as resubmitted by the authors on 17 January 2010. 